\title{
Magnetic And pH Dual-Responsive Nanoparticles For Synergistic Drug-Resistant Breast Cancer Chemo/Photodynamic Therapy
}

This article was published in the following Dove Press journal: International Journal of Nanomedicine

\author{
Dan Wang ${ }^{1,2, *}$ \\ Xuefen $\mathrm{Li}^{3, *}$ \\ Xinfang $\mathrm{Li}^{4, *}$ \\ Anfeng Kang ${ }^{4}$ \\ Linhong Sun ${ }^{4}$ \\ Miao Sun ${ }^{4}$ \\ Feng Yang ${ }^{4}$ \\ Congjian $\mathrm{Xu}{ }^{\prime}$
}

'Shanghai Key Laboratory of Female Reproductive Endocrine Related Disease, Obstetrics and Gynecology Hospital, Fudan University, Shanghai, People's Republic of China; ${ }^{2}$ Department of Gynaecology and Obstetrics, Changzheng Hospital, Second Military Medical

University, Shanghai, People's Republic of China; ${ }^{3}$ Department of Nephrology, Jiulongpo People's Hospital, Chongqing, People's Republic of China; ${ }^{4}$ Inorganic Chemistry Department, School of Pharmacy, Second Military Medical University, Shanghai, People's Republic of China

*These authors contributed equally to this work

\begin{abstract}
Background: Drug resistance is one of the prime reasons of chemotherapy failure in breast cancer and is also an important factor affecting prognosis.

Purpose: In this study, we constructed a functional magnetic mesoporous silica-based nanocomposite (MMSN) for breast cancer chemotherapy/photodynamic therapy.

Methods: MMSN was characterized by scanning electron microscopy and transmission electron microscopy to observe the morphology. The size distribution and zeta potential of the MSNs were determined using Malvern Particle Size Analyzer. Anti-tumor activity in vitro was investigated by CCK- 8 assay, flow cytometry and transwell experiment, and the anti-tumor activity in vivo was probed into by magnetic targeting, toxicity, and antitumor effects in breast cancer-bearing BABL/c nude mice.

Results: The results showed that the release of doxorubicin in the nanocomposites was $\mathrm{pH}$ sensitive, and the cumulative release rate reached $80.53 \%$ at $60 \mathrm{~h}$ under acidic conditions. The nanocomposites had a high cellular uptake ability in MCF-7/ADR cells, and the $\mathrm{IC}_{50}$ value of the nanocomposites on MCF-7/ADR cells was $4.23 \mu \mathrm{g} / \mathrm{mL}$, much smaller than that of free DOX $(363.2 \mu \mathrm{g} / \mathrm{mL})$. The nanocomposites could effectively reverse resistance and induce apoptosis of MCF-7/ADR cells. The blood biochemistry parameters and H\&E staining results showed no serious adverse effects after treatment with the nanocomposites. Prussian blue staining showed that the nanocomposites were able to target tumor tissues in tumor-bearing mice under a magnetic field. The combined chemical/photodynamic therapy significantly inhibited tumor growth in vivo.
\end{abstract}

Conclusion: Nanocomposites with magnetic and $\mathrm{pH}$ dual-responsive performance has shown a promising platform for enhanced drug-resistant breast cancer treatment.

Keywords: magnetic mesoporous silica, doxorubicin, magnetic targeting, $\mathrm{pH}$ responsive, photodynamic therapy

\section{Introduction}

Breast cancer is one of the most common malignant tumors and a grievous threat to women's health worldwide. ${ }^{1}$ Breast cancer accounts for $30 \%$ of all new cancer diagnoses and has a mortality rate that is the second highest among all women with malignant tumors in the USA. ${ }^{2}$ With the progression of this disease, traditional therapies such as surgery, radiotherapy, and chemotherapy are difficult to obtain satisfactory therapeutic effects due to low bioavailability, adverse effects, poor patient compliance, and drug resistance. $^{3,4}$ In recent years, photodynamic therapy (PDT), combined with chemotherapy, has become an available technique for cancer treatment. ${ }^{5,6}$ Yoon et $\mathrm{al}^{7}$ have found

Congjian Xu

Department of Gynecology, Obstetrics and Gynecology Hospital, Fudan University, 419 Fangxie Road, Shanghai 2000 I I, People's Republic of China Tel +862133189900

Email xucongjian@fudan.edu.cn 
that PDT with ALA-hx (hexenyl ester of 5-aminolaevulinic acid) more efficiently produced reactive oxygen species (ROS) and suppressed MCF-7/ADR cells viability; the findings suggest that ALA-hx PDT may be used as a therapeutic alternative for drug-resistant breast cancer. ${ }^{7}$ In addition, the combination of PDT and chemotherapy always has potential advantages compared with traditional treatments, such as high selectivity, minimal invasiveness, and effectiveness in overcoming chemotherapy drug resistance. ${ }^{8-10}$

An effective drug delivery system with strong drugloading ability, controlled drug release, and tumor targeting is the key success factors of combination therapy. ${ }^{11-13}$ Nano-scaled carriers including micelles, ${ }^{14}$ liposomes, ${ }^{15}$ and inorganic nanoparticles, ${ }^{16}$ which have been proved that it could increase the delivery efficiency and reduce the side effects of chemotherapy drugs, would be a good cooperative therapy for cancer treatments. ${ }^{17}$ Mesoporous silica nanoparticles (MSNs) show unique characteristics, such as large pore volumes and surface areas, tunable pore diameters and sizes, easy functionalization, robustness, and good biocompatibility. ${ }^{18-20}$ These properties have attracted increasing attention and interest to the research and application of MSNs in new nanodrug-loading systems.

In this study, we prepared nanocomposites based on magnetic mesoporous silica nanoparticle (MMSN) to deliver the photosensitizer chlorin e6 (Ce6) and doxorubicin hydrochloride (DOX). To reduce the toxicity and leakage of DOX during the drug transport, a $\mathrm{pH}$-responsive polymeric compound was synthesized for grafting onto the surface of the MMSN. Thus, the nanocomposites were provided with magnetic and $\mathrm{pH}$ dual-responsive capabilities and achieved tumor-targeted chemotherapy/photodynamic therapy, controlled drug release, and reduced side effects.

As shown in Figure 1, the magnetic and $\mathrm{pH}$ dual-responsive nanocomposites [Ce6@MMSN/DOX@FA-PEG- $b$ PAsp, folate polyethylene glycol- $b$-poly(asparaginyl-chidamide)] were synthesized for photodynamic chemotherapy. DOX was loaded as a chemotherapy drug and released under the control of $\mathrm{pH}$-responsive polymer FA-PEG- $b$ PAsp. The therapeutic potential and mechanisms of the nanocomposites in vitro and in vivo were further evaluated. The results confirmed the highly efficient antitumor characteristics of the nanocomposites for treating human MCF-7/ADR tumor cells and tissues, thus providing a fascinating opportunity for drug-resistant cancer treatments.

\section{Materials And Methods Synthesis Of MSNs And Amine Functionalization}

The multistep synthesis of MSNs was based on a similar Stöber process in alkali water solution. ${ }^{21}$ First, cetyltrimethylammonium bromide (CTAB) (1 g) aqueous solution was prepared with $160 \mathrm{~mL}$ of deionized water and ammonia water (3 mL, 28 wt. \%) was added by dripping slowly. After $30 \mathrm{~min}$ of high-speed stirring (300 rpm), a clear solution was formed at $35^{\circ} \mathrm{C}$. Then, a mixture solution of tetraethyl orthosilicate (TEOS) $(4 \mathrm{~mL})$ and $n$-hexane $(20 \mathrm{~mL})$ was added dropwise into the solution, and the mixture gradually became a homogenous milky

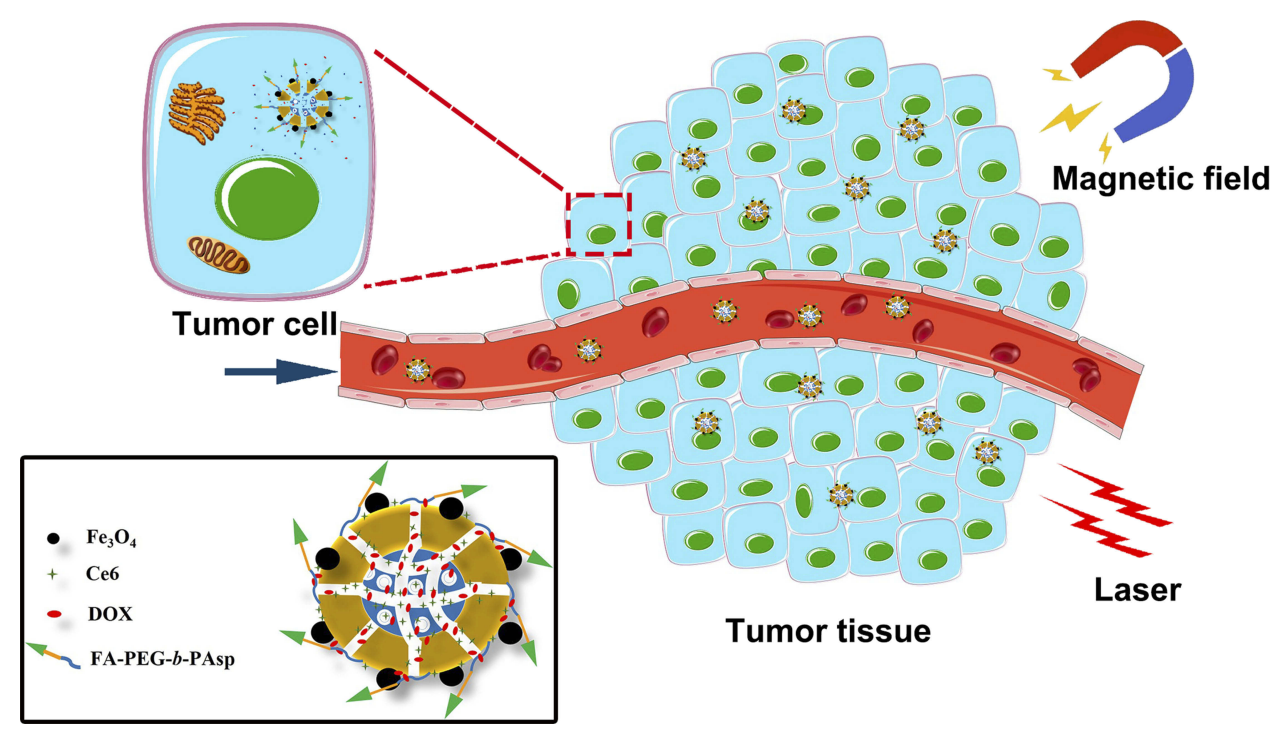

Figure I The scheme of nanocomposite/photodynamic chemotherapy in tumor tissues and cells. Abbreviations: Ce6, chlorin e6; DOX, doxorubicin hydrochloride. 
colloidal solution. ${ }^{22}$ The product was centrifuged $(7000$ $\mathrm{rpm}, 10 \mathrm{~min}$ ) after stirring for $12 \mathrm{~h}$, and washed thrice with deionized water and ethanol thrice. Next, CTAB was removed according to a previously reported procedure. ${ }^{23}$ Briefly, the collected product (ie, mesostructured $\mathrm{CTAB} /$ silica composite) was refluxed at $90^{\circ} \mathrm{C}$ for $5 \mathrm{~h}$ by dispersing in a mixture of ethanol $(100 \mathrm{~mL})$ and $5 \mathrm{M} \mathrm{HCl}(2 \mathrm{~mL})$. The solvent extraction was repeated thrice, and the mixture was collected by centrifuging and washing. Thus, ordered MSNs were eventually obtained after vacuum drying overnight. Finally, the MSNs $(200 \mathrm{mg}$ ) were redispersed in anhydrous ethanol $(100 \mathrm{~mL})$ at $30^{\circ} \mathrm{C}$, then (3-aminopropyl)triethoxysilane (APTES) $(200 \mu \mathrm{L})$ was gradually added to the mixture under a $\mathrm{N}_{2}$ gas atmosphere. ${ }^{24}$ The mixture was subsequently centrifuged after stirring for $12 \mathrm{~h}$ and washed twice to dislodge unreacted APTES. Finally, MSN-NH $\mathrm{N}_{2}$ was collected after drying under vacuum.

\section{Preparation Of Ce6@MMSN}

Monodisperse iron oxide nanocrystals were synthesized based on an oleic acid/water/alcohol system (Supplementary Materials) as reported before. ${ }^{25}$ The ligand-exchanged $\mathrm{Fe}_{3} \mathrm{O}_{4}$ nanocrystals were synthesized via ligand exchange reactions (Supplementary Materials) ${ }^{26}{ }^{26}$ The oleic groups on the iron oxide nanocrystal surfaces were replaced by 2-bromo-2-methylpropionic acid (BMPA). The $\mathrm{MSN}-\mathrm{NH}_{2}$ was reacted with the ligand-exchanged $\mathrm{Fe}_{3} \mathrm{O}_{4}$ nanocrystals. ${ }^{27}$ Specifically, $70 \mathrm{mg}$ of $\mathrm{MSN}-\mathrm{NH}_{2}$ nanoparticles was dispersed ultrasonically in $50 \mathrm{~mL}$ anhydrous ethanol. Then, $10 \mathrm{~mL}$ of the ligand-exchanged $\mathrm{Fe}_{3} \mathrm{O}_{4}$ nanocrystal dispersion was added into the system. Next, the system was stirring for $12 \mathrm{~h}$ at $30^{\circ} \mathrm{C}$ under a $\mathrm{N}_{2}$ gas atmosphere. The nanoparticles were subsequently retrieved and washed thrice by means of a neodymium, iron, and boron (NIB) magnet (Dongguan Fuqiang Magnetic Industry Co. Ltd., China) to remove excess $\mathrm{Fe}_{3} \mathrm{O}_{4}$ nanocrystals. The MMSNs were dried in vacuum. In the next step, N,N-dicyclohexylcarbodiimide (DCC) was used to ensure that the carboxylic groups of $\mathrm{Ce} 6$ selectively reacted with the amino groups of MMSN. ${ }^{28}$ Briefly, $50 \mathrm{mg}$ of MMSNs was dispersed in $20 \mathrm{~mL} \mathrm{~N}$, N-dimethylformamide (DMF). Then, $10 \mathrm{mg}$ of Ce6 and $75 \mathrm{mg}$ of DCC were added. After stirring in the dark for $24 \mathrm{~h}$ at $25^{\circ} \mathrm{C}$, the nanoparticles were collected by the NIB magnet and washed thrice with DMF. Finally, the Ce6@MMSN were obtained after drying in vacuum. In addition, the supernatant was collected to determine the loaded amount of Ce6 by UV/vis spectrum (Lambda25; PerkinElmer, Waltham, MA, USA).

\section{Preparation Of Ce6@MMSN/DOX@FA- PEG-b-PAsp}

FA-PEG- $b$-PAsp was synthesized according to previous methods (Supplementary Materials). ${ }^{29,30}$ After $20 \mathrm{mg}$ of Ce6@MMSN was dispersed in deionized water $(4 \mathrm{~mL})$, NHS $(4 \mathrm{mg})$ and EDC $\cdot \mathrm{HCl}(16 \mathrm{mg})$ were added at a 300 rpm stirring speed. Next, 40 mg FA-PEG- $b$-PAsp dissolved in $6 \mathrm{~mL}$ deionized water was added into the mixture. After the mixture continued to react for $4 \mathrm{~h}$ in an ice bath in the dark, $4.4 \mathrm{~mL}$ of a DOX $\cdot \mathrm{HCl}(5 \mathrm{mg} / \mathrm{mL})$ aqueous solution was added. After stirring for $24 \mathrm{~h}$, the final product was obtained after dialysis and lyophilization.

\section{Characterization Of The Materials}

Different techniques were used to characterize the prepared materials. A Philips XL-30 scanning electron microscope (SEM) was used to determine the morphology of the MSNs. Transmission electron microscope (TEM) (JEM2011, JEOL, Japan) was employed to closely observe the material morphology; the TEM operated at $200 \mathrm{kV}$. The size distribution and zeta potential of the MSNs were determined using Malvern Particle Size Analyzer (Zeta sizer Nano ZS, Malvern, UK). The UV-vis spectrometer (Lambda 25; Perkin Elmer, USA) was used to record the UV-vis spectra. The pore size of the MSNs was evaluated by the Brunauer-EmmettTeller (BET) method (Micromeritics, Atlanta, GA, USA). Magnetic characterization was conducted with a vibrating sample magnetometer (VSM, San Jose, USA) at $300 \mathrm{~K}$. Biological TEM (H-7650; Hitachi, Tokyo, Japan) was used to observe the cellular uptake.

\section{Determination Of DOX-Loading Efficiency And In Vitro Release}

To determine theDOX-loading, $5 \mathrm{mg}$ of the above-prepared Ce6@MMSN/DOX@FA-PEG- $b$-PAsp was ultrasonically dispersed in phosphate-buffered saline (PBS; pH 5.5). After stirring for $24 \mathrm{~h}$ under dark conditions, the mixture was centrifuged; the DOX content of the supernatant was determined by a UV-vis spectrum at $481 \mathrm{~nm} .{ }^{31}$ The DOX-loading rate $(\%)=$ (mass of DOX in Ce6@MMSN/DOX@FA-PEG- $b$-PAsp/total mass of the Ce6@MMSN/DOX@FA-PEG- $b$-PAsp)

DOX release from the nanocomposites was determined in PBS with different $\mathrm{pH}$ values $(\mathrm{pH} 5.5,7.4)$ to simulate 
tumor and normal microenvironments. Briefly, $5 \mathrm{mg}$ of the above-prepared martials was dispersed and dialyzed against both PBS media. Then, the dispersions were shaken at 200 rpm under dark conditions. At a predetermined sampling time, the suspension was collected and adequate amounts of fresh media were added. Finally, quantities of DOX were determined by UV-vis spectroscopy.

\section{Magnetic Targeting And Cellular Uptake In Vitro}

Human breast cancer cell line MCF-7/ADR was kindly presented by Professor $\mathrm{Lu}$ Wanliang from Peking University (Beijing, China), and cell experiments were conducted in compliance with the Guiding Principles for the research ethics on human cells and approved by the Ethics Committee of the Second Military Medical University. The MCF-7/ADR cells were incubated in RPMI-1640 culture medium with $10 \% \mathrm{FBS}$ at $37^{\circ} \mathrm{C}$ with $5 \% \mathrm{CO}_{2}$. For magnetic targeting in vitro, the MCF-7/ADR cells were seeded onto microscope coverslips at a density of $10^{5}$ per slide and incubated in two 10-cm culture dishes. MSNs $(20 \mu \mathrm{g} / \mathrm{mL})$ and Ce6@MMSN/DOX @FA-PEG-b-PAsp (20 $\mu \mathrm{g} / \mathrm{mL})$ were added, and then an NIB magnet was placed under one coverslip. After incubation for $2 \mathrm{~h}$ (swaying the dishes every $20 \mathrm{~min}$ ), the cells were washed thrice with PBS, and the fluorescence intensity $\left(\lambda_{\mathrm{ex}}=495 \mathrm{~nm}, \lambda_{\mathrm{em}}=595 \mathrm{~nm}\right)$ was detected via flow cytometry (BD Biosciences, USA).

To study cellular uptake, the MCF-7/ADR cells were plated in six-well culture plates at a density of $10^{5}$. After incubating for $12 \mathrm{~h}$, the cells were treated with free DOX, Ce6@MMSN/DOX@PEG-b-PAsp or Ce6@MMSN/ DOX@FA-PEG-b-PAsp (10 $\mu \mathrm{g} / \mathrm{mL}$ DOX). After incubation for $2 \mathrm{~h}$, the cells in each well of the culture plates were washed, then fixed with $4 \%$ paraformaldehyde and stained with 4',6diamidino-2-phenylindole (DAPI). Then, the cells were inspected by fluorescence microscopy (IX71; Olympus Corporation, Tokyo, Japan). Additionally, cellular uptake was investigated by biological TEM. Briefly, the MCF-7/ ADR cells were incubated in a $10-\mathrm{cm}$ dish, and the culture medium was discarded when the culture dish was covered by cells. Then, Ce6@MMSN/DOX@FA-PEG-b-PAsp (50 $\mu \mathrm{g}$ / $\mathrm{mL}, 8 \mathrm{~mL}$ ) was added to the culture dish. After incubation for $4 \mathrm{~h}$, the cells were collected and fixed with $2.5 \%$ glutaraldehyde. After keeping $4-6 \mathrm{~h}$ at $4^{\circ} \mathrm{C}$, the samples were observed by the biological TEM.

\section{Cytotoxicity, Apoptosis Assay, And Transwell Experiment}

The CCK-8 assay was used to evaluate the cytotoxicity of the nanoparticles. Briefly, these cells were seeded into 96-well plates. Twelve hours later, free DOX and Ce6@MMSN/ DOX@FA-PEG- $b$-PAsp were added at different DOX concentrations ( 0.1 to $200 \mu \mathrm{g} / \mathrm{mL}$ ). After incubating for $12 \mathrm{~h}$ in dark, one plate was irradiated with $660 \mathrm{~nm}$ light for $3 \mathrm{~min}$, and then the plate incubated for another $12 \mathrm{~h}$. Finally, $10 \mu \mathrm{L}$ of CCK- 8 was added and the plates were subjected using a microplate reader (ELx800; BioTek, USA) at $450 \mathrm{~nm}$.

To measure the cellular apoptosis, a total of $3 \times 10^{5} \mathrm{MCF}$ 7/ADR cells were seeded into 6-well plates. Then, the cells were incubated with MSNs, free DOX, and nanocomposites for $24 \mathrm{~h}$. Next, the cells were stained with the FITC Annexin V-APC/PI Kit (Shanghai Biotend Technology Co. Ltd., Shanghai, China). The samples were analyzed using FACS.

For the Transwell experiment, the MCF-7/ADR cells seeded into 6-well flat-bottomed plates with a density of $3 \times 10^{5}$ cells/well. After culturing for $12 \mathrm{~h}$, the medium in each well was removed, and nanocomposites with various DOX concentrations $(0,0.5,2.0$, and $10.0 \mu \mathrm{g} / \mathrm{mL})$ in RPMI-1640 medium were added. After incubated for 24 $\mathrm{h}$, the cells were resuspended in serum-free RPMI-1640 medium and adjusted to $1 \times 10^{5}$ cells $/ \mathrm{mL}$. Subsequently, cell suspension $(200 \mu \mathrm{L})$ was plated into the Transwell inserts, and RPMI-1640 medium containing 20\% FBS $(800 \mu \mathrm{L})$ was placed in the bottom wells of the Transwell plates. Then, the plates were incubated for 24 h. After fixing the cells with the prepared cellular fixative ( $4 \%$ glutaraldehyde) for $15 \mathrm{~min}$, the samples were stained with $0.1 \%$ crystal violet. Finally, the samples were examined under a light microscope (Olympus IX71 fluorescence microscope).

\section{Magnetic Targeting, Toxicity, And Antitumor Effects In Vivo}

All animal experiments were approved by the Ethics Committee of the Second Military Medical University and conducted in compliance with the Guiding Principles for the Care and Use of Laboratory Animals, the Second Military Medical University. Protocols were approved by the Institutional Animal Care and Use Committee of the Second Military Medical University. For the in vivo experiments, a BABL/c nude mouse transplanted tumor model was established first. Nude mouse breast cancer model was 
prepared by injecting $2 \times 10^{6}$ MCF-7/ADR cells $(100 \mu \mathrm{L}$ culture medium) into the fat pad of the fourth breast. Until the tumor volume was approximately $200 \mathrm{~mm}^{3}$, the mice were randomly divided into two groups. The nanocomposites $(18 \mathrm{mg} / \mathrm{kg})$ were given by intravenous injection, while normal saline solution was injected as control. $\mathrm{T}_{1}$-weighted images were obtained by an MRI scanner (MesoMR23060H-I, Niumai Electric Technology Co. Ltd., Shanghai, China) at two time points ( $2 \mathrm{~h}$ postinjection and $2 \mathrm{~h}$ postinjection with NIB magnet for $30 \mathrm{~min}$ ). Additionally, mice were executed to analyze the iron distribution in the main organs and tumor tissues by Prussian blue staining.

To study the toxicity effect of the nanocomposite, 15 healthy mice were divided into three groups. The mice were intravenously injected with $0.1 \mathrm{~mL} / 10 \mathrm{~g}$ MSNs or nanocomposites $(1 \mathrm{mg} / \mathrm{mL})$ per day. Mice injected with normal saline solution were used as control. Twenty-four hours after the last treatment, the ocular serum was collected for blood biochemistry, and the mice were executed by cervical vertebra dislocation. The main organs were dissected and fixed in 4\% paraformaldehyde. Finally, the samples were stained with hematoxylin and eosin (H\&E) and examined by fluorescence microscopy.

To investigate the antitumor activity of the nanocomposites in vivo, MCF-7/ADR tumor-bearing BALB/c nude mice were treated with normal saline solution (control), free DOX, nanocomposites without NIB magnet (nanocomposites-), and nanocomposites within NIB magnet (nanocomposites + ). The drugs were injected into mice via the tail vein $(3.0 \mathrm{mg} \mathrm{DOX} / \mathrm{kg})$. Moreover, the NIB magnet was combined with the tumor sites for $2 \mathrm{~h}$ in the nanocomposites + group. Afterward, the tumor sites of all mice were irradiated by $660 \mathrm{~nm}$ light at $10 \mathrm{~J} / \mathrm{cm}^{2}$ for $5 \mathrm{~min}$ every 2 days. The tumor volume was calculated by the following equation: length $\times$ width $^{2} / 2$. Furthermore, the body weights and survival rates were recorded.

\section{Statistical Analysis}

The data are expressed as the mean $\pm \mathrm{SD}$. Intergroup differences were analyzed by Dunnett's $t$-test, and $\mathrm{P}<0.05$ indicates a statistically significant difference.

\section{Results And Discussion Characterization Of Nanoparticles}

The MSN was prepared via a modified Stöber process using CTAB as the template, TEOS as the silicon source, and $n$-hexane as the pore-expanding agent. SEM images revealed that the prepared MSN had a favorable spherical morphology (approximately $100 \mathrm{~nm}$ ) with good dispersion without aggregation (Figure 2A). TEM images (Figure 2B) indicated that the obtained MSNs were highly dispersed and had a uniform spherical morphology with a diameter of $100 \mathrm{~nm}$, which agrees well with the SEM results. The FTIR results showed that the CTAB could be completely dislodged by the ethanol extraction (Figure S1). Highmagnification TEM showed that the MSN had a special core-shell structure (Figure 2C). As estimated from the images, the core was approximately $80 \mathrm{~nm}$ in diameter, and the shell was approximately $10 \mathrm{~nm}$ in thickness. This unique core-shell structure was formed by the slowing reaction rate at lower concentrations of basic catalyst, which caused the gradual growth of the mesostructure by stepwise deposition of a layer of porous shell with radially aligned mesopores on the MSN nanoseed. ${ }^{22}$ The merit of this unique mesoporous structure was that the MSN nanoseed has the ability to load and bind multiple drugs to achieve sustained- and controlled-release effects. Therefore, MSN could be designed as an efficient multidrug delivery system.

Using a liquid-solid-solution method, ${ }^{32}$ we prepared nearly monodisperse iron oxide nanocrystals using $\mathrm{FeSO}_{4}(\mathrm{NH})_{4} \mathrm{SO}_{4} \cdot 6 \mathrm{H}_{2} \mathrm{O}$ as the raw materials. The TEM image (Figure 2D) shows that the $\mathrm{Fe}_{3} \mathrm{O}_{4}$ nanoparticles are uniform with $10 \mathrm{~nm}$ in diameter of, and the nanoparticles are highly dispersed without aggregation. Figure 2E shows the TEM images of the synthesized MMSN. Clearly, the $\mathrm{Fe}_{3} \mathrm{O}_{4}$ nanocrystals were immobilized on the MSN, and the MMSNs were discrete and uniform; ordered mesopores were also clearly visible. The successful grafting of Ce6 onto the MMSNs was confirmed by the UV/vis absorption spectra, from which the characteristic Ce6 absorption peaks were clearly identified (Figure S2). The polymer FA-PEG- $b$-PAsp was grafted onto MMSNs by amidation reaction. The TEM images showed the successful grafting of FA-PEG- $b$-PAsp onto the mesoporous silica surface (Figure 2F). The morphology of the final nanocomposite (Ce6@MMSN/DOX@FA-PEG-b-PAsp) was uniform with well-ordered mesopores. The PAsp end in the polymer can act as a pH-responsive release switch under acidic and neutral conditions, while the PEG end increases the hydrophilicity of coloaded drug nanocomposites.

The size distribution of the MSNs was characterized by DLS. The average sizes were in the range of 135-145 nm (Figure 2G), which contributed to a satisfactory drug 

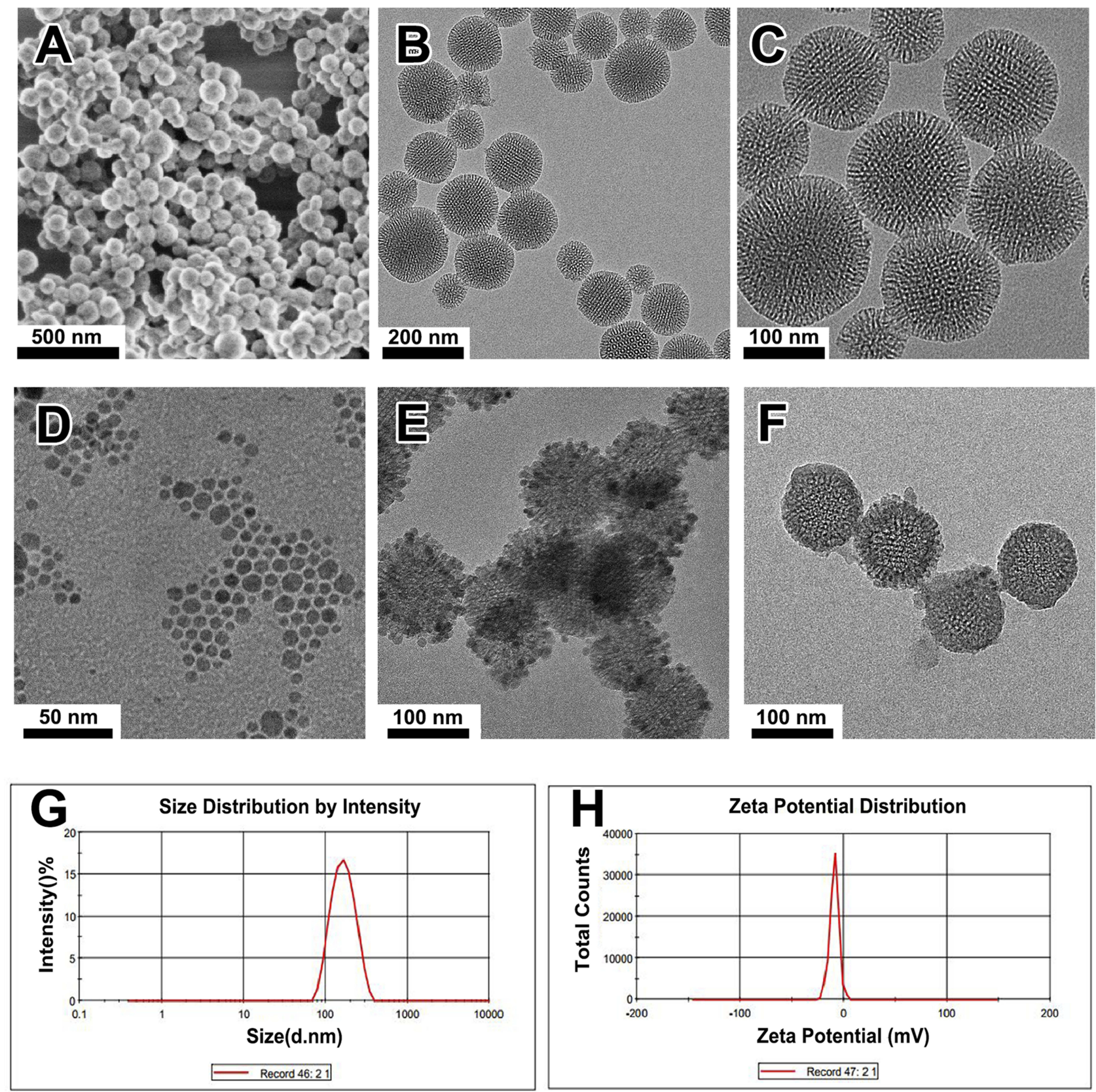

Figure 2 The structural characterization of the samples.

Notes: (A) SEM image of MSN. (B, C) TEM images of MSN. (D, E, F) TEM images of the $\mathrm{Fe}_{3} \mathrm{O}_{4}$ nanocrystals, MMSN, and nanocomposite. (G) Particle size of the MSN determined by DLS. (H) Zeta potential of the MSN determined by DLS.

Abbreviations: TEM, transmission electron microscope; SEM, scanning electron microscope; DLS, dynamic light scattering; MMSN, magnetic mesoporous silica nanoparticle.

accumulation through the enhanced permeability and retention (EPR) effect. ${ }^{33,34}$ The zeta potential of the MSNs was $-9.21 \pm 1.4 \mathrm{mV}$ (Figure $2 \mathrm{H}$ ), which is propitious for strong electrostatic interactions between the cell membranes and nanocomposites for higher uptake efficiency. ${ }^{35}$

To explore the details of the mesoporous structure of the MSN, nitrogen desorption-adsorption tests were carried out. As shown in Figure 3A, the isothermal curve is similar to the type IV isotherm as defined by the International Union of Pure and Applied Chemistry (IUPAC). The hysteresis loop indicated that the MSN possessed a mesoporous architecture. The total pore volume was $2.47 \mathrm{~cm}^{3} / \mathrm{g}$, and the BET specific surface area was $1375 \mathrm{~m}^{2} / \mathrm{g}$. The pore size was $5.36 \mathrm{~nm}$ with a relatively narrow pore size distribution. All these properties ensured that the drugs were efficiently loaded into the nanocomposites. 

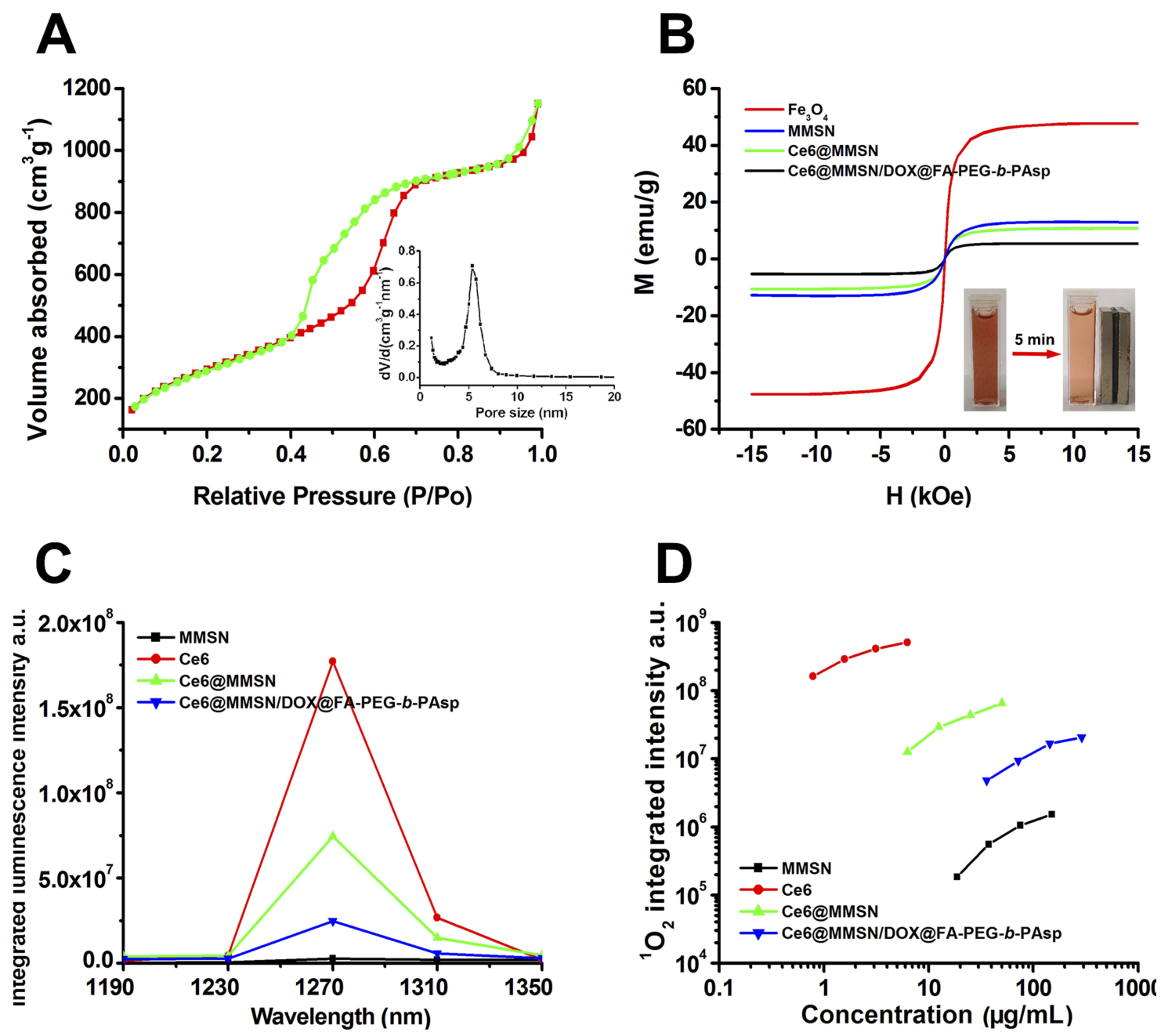

Figure 3 Characterization of the nanocomposites.

Notes: (A) Nitrogen absorption/desorption isotherms of MSN. Inset: the pore size distributions of MSN. (B) Hysteresis loop of samples normalized to the mass by VSM. Inset: photographs of a nanocomposite aqueous solution without (left) and with (right) magnetic field. (C) Near-infrared spectrogram of the samples. (D) Singlet-oxygen production of the samples in DMF.

Abbreviations: MSN, mesoporous silica nanoparticle; DMF, N,N-dimethylformamide; NIB, neodymium, iron, and boron magnet.

The magnetic properties of $\mathrm{Fe}_{3} \mathrm{O}_{4}, \mathrm{MMSN}, \mathrm{Ce} 6 \mathrm{MMSN}$, and Ce6@MMSN/DOX@FA-PEG- $b$-PAsp were measured, as shown in Figure 3B, the samples exhibited typical superparamagnetic behaviors due to the absence of hysteresis loops, zero remanence, and coercivity. Although the saturation magnetization of Ce6@MMSN/DOX@FA-PEG-b-PAsp (5.3 emu/g) was clearly reduced compared with that of $\mathrm{Fe}_{3} \mathrm{O}_{4}$ (47.6 emu/g), the nanocomposites were quickly assembled (Figure 3B, inset) after exposure to a magnetic field for $5 \mathrm{~min}$.

Singlet oxygen $\left({ }^{1} \mathrm{O}_{2}\right)$ is a critical factor and its production directly affects the efficiency of PDT. ${ }^{36}$ A near-infrared spectrogram (Figure 3C) reveals that the luminescence signal of the photosensitizer is the strongest at $1270 \mathrm{~nm}$. Figure 3D shows that the singlet-oxygen production of free Ce6 was the highest, while that of the nanocomposites was the lowest. The main reason may be that the covalent crosslinking of photosensitizers affected the production of singlet oxygen and attenuated the fluorescence intensity. However, the nanocomposites still exhibited good cytotoxicity after laser irradiation.

\section{$\mathrm{pH}$-Responsive Release Behavior In Vitro}

The merit of a drug delivery system with different nanoparticles is that it can be used to control drug release, which could decrease the drug toxicity and improve the drug bioavailability. Figure 4A shows the UV absorption spectra of free DOX solutions; $481 \mathrm{~nm}$ was chosen as the characteristic absorption wavelength of DOX. The $\mathrm{pH}-$ responsive release of DOX from the nanocomposites was measured by dialysis tube and UA analysis. The 

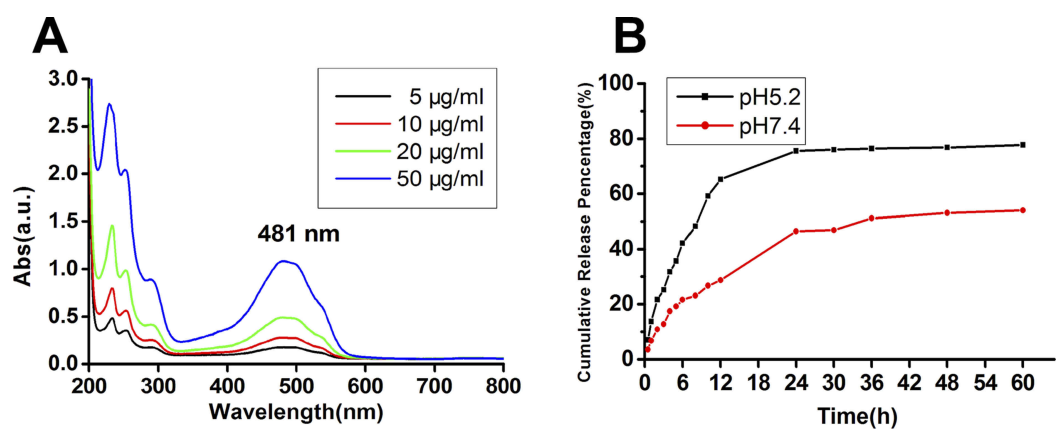

Figure 4 DOX release performance of the nanoparticles.

Notes: (A) UV absorption spectra of free DOX. (B) pH-responsive release profiles of the DOX in vitro.

Abbreviations: DOX, doxorubicin hydrochloride; MMSN, magnetic mesoporous silica nanoparticle.

nanocomposites were dispersed in PBS $(\mathrm{pH}=5.2,7.4)$ at room temperature, simulating the acidic tumor and normal microenvironments. The cumulative release performance is shown in Figure 4B. The release rate of DOX had an obvious $\mathrm{pH}$ responsiveness and was more efficient at the $\mathrm{pH}$ value of 5.2 solution. Approximately $80.53 \%$ of the DOX was released over $24 \mathrm{~h}$ at a $\mathrm{pH}$ value of 5.2, while only $53.98 \%$ of the DOX was released even over $60 \mathrm{~h}$ at a $\mathrm{pH}$ value of 7.4. In the neutral environment, the polymer strongly interacted with mesoporous silicon and surrounded the latter surface tightly, which wrapped DOX in the mesopores and avoided its divulgement, while the PAsp segments of the polymer became hydrophilic and loose in an acid condition, exposing the mesoporous channels in the cytoplasm; hence, DOX could be released rapidly. These results demonstrated that grafting an amphiphilic block copolymer onto the mesoporous surface endowed the nanocomposites with $\mathrm{pH}$ responsiveness, which could reduce DOX release in normal tissues and could play a more effective antitumor role. In sum, the nanocomposites were a promising codelivery system for drug combination in cancer treatments.

\section{Cellular Uptake And Magnetic Targeting In Vitro}

The effective cellular uptake of nanomaterials is important for efficient drug delivery. ${ }^{37,38}$ Hence, fluorescence microscopy was used to detect the cellular uptake of free DOX, Ce6@MMSN/DOX@PEG-b-PAsp, and Ce6@MMSN/DOX @FA-PEG- $b$-PAsp in MCF-7/ADR cells (Figure 5A). Fluorescence signals observed in MCF-7/ADR cells treated with nanocomposites were significantly stronger compared with those treated with free DOX (the free RB group demonstrated little red fluorescence) after $2 \mathrm{~h}$ of incubation. In addition, the TEM data confirmed that Ce6@MMSN/ DOX@FA-PEG- $b$-PAsp was well endocytosed by the MCF7/ADR cells (Figure 5B). The nanocomposites clearly existed in the cells as small aggregates located in the cytoplasm. ${ }^{39}$ Those results confirmed that the nanocomposites could be efficiently delivered into living cells.

In vitro magnetic targeting of the nanocomposites was examined with MCF-7/ADR cells using flow cytometry (Figure $5 \mathrm{C}$ ). After $2 \mathrm{~h}$ of exposure to a magnetic field, the mean DOX fluorescence of the nanocomposite group $\left(X_{\text {mean }}=292.94\right)$ was much higher than that of the nanocomposite group without a magnetic field $\left(X_{\text {mean }}=201.56\right)$ and that of the control group $\left(X_{\text {mean }}=9.96,9.80\right)$. The results showed that the nanocomposites have good magnetic targeting and drug-release ability in vitro.

\section{Cytotoxicity And Apoptosis Assays}

The cytotoxicity of the nanocomposites was measured to study the treatment effect in MCF-7/ADR cells in vitro. First, the photodynamic killing efficacy of the nanocomposites was measured using the CCK- 8 assay; the cells were incubated with the nanocomposites at a DOX concentration from $0.5 \mu \mathrm{g} / \mathrm{mL}$ to $10 \mu \mathrm{g} / \mathrm{mL}$ and irradiated by NIR light $\left(10 \mathrm{~J} / \mathrm{cm}^{2}\right.$ for $\left.3 \mathrm{~min}\right)$. As shown in Figure $6 \mathrm{~A}$, no significant toxicity was observed after 24-h incubation with free DOXin the MCF-7/ADR cells. In groups treated with nanocomposites, cytotoxicity was observed to be dose dependent. In addition, photodynamic killing was evident in the irradiated cells compared with those without NIR irradiation.

The half-maximal inhibitory concentration $\left(\mathrm{IC}_{50}\right)$ was calculated (Figure 6B). According to the $\mathrm{IC}_{50}$ fitted curve, the $\mathrm{IC}_{50}$ values of free $\mathrm{DOX}$ and nanocomposites in $\mathrm{MCF}-7 /$ ADR cells (Figure 6Ba) were $363.2 \mu \mathrm{g} / \mathrm{mL}$ and $4.23 \mu \mathrm{g} / \mathrm{mL}$, respectively. Obviously, the cytotoxicity of the nanocomposites was significantly higher than that of free DOX at 


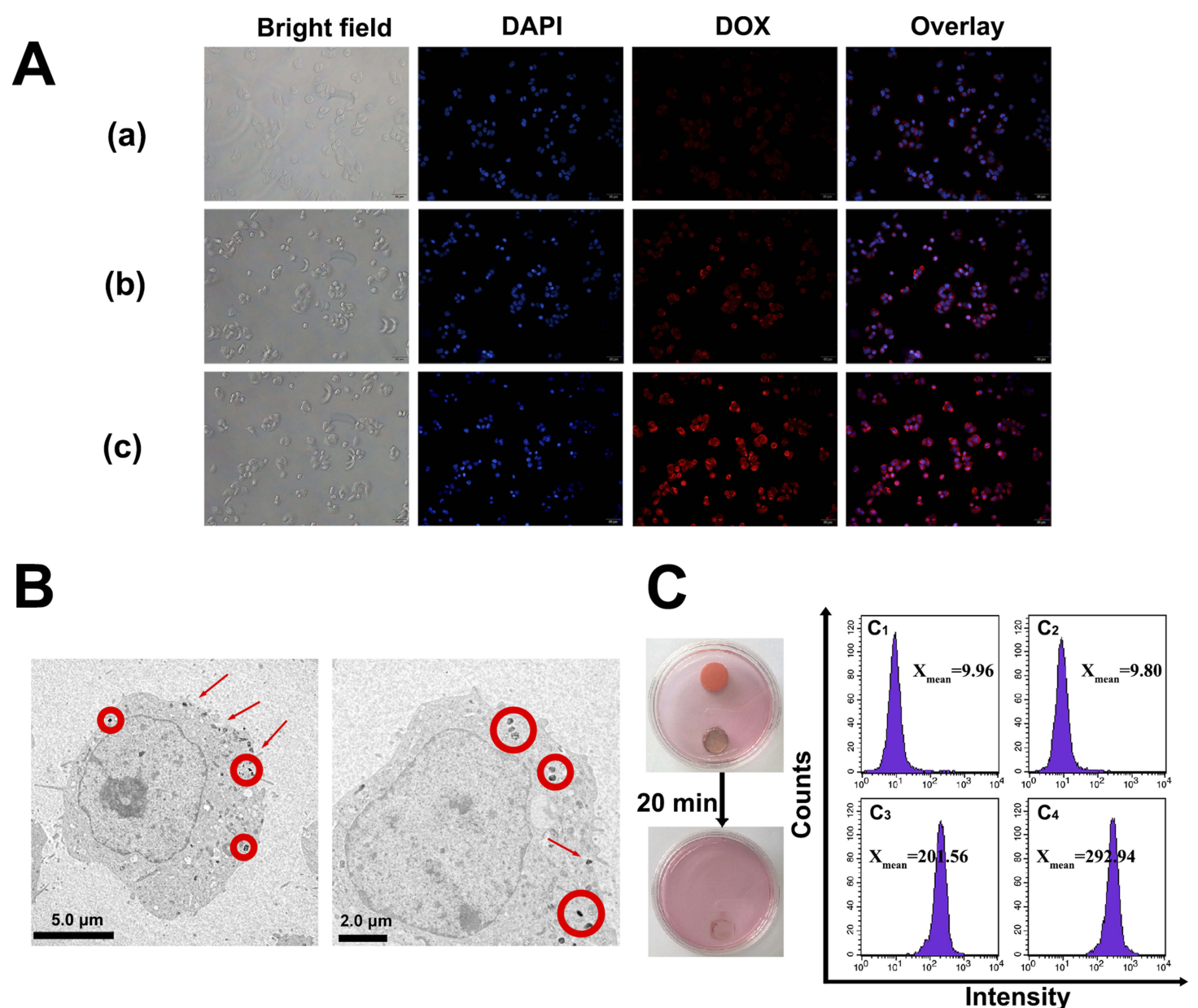

Figure 5 Cellular uptake of nanoparticles.

Notes: (A) Fluorescence images of MCF-7/ADR cells after 2-h incubation with DOX (a), Ce6@MMSN/DOX@PEG-b-PAsp (b), and Ce6@MMSN/DOX @FA-PEG-b-PAsp (c). (B) Biological TEM images of MCF-7/ADR cells treated with nanocomposites for $2 \mathrm{~h}$. The circles and arrows indicate the locations of the nanoparticles. (C) The fluorescence intensity of MCF-7/ADR cells cultured under different conditions (right), CI, blank cell; C2, MSN; C3, nanocomposites without magnetic field; C4, nanocomposites within magnetic field; photographs of culture dishes containing MCF-7/ADR cells (left).

Abbreviations: TEM, transmission electron microscope; DAPI, 4',6-diamidinio-2-phenylindole; DOX, doxorubicin hydrochloride; Ce6, chlorin e6.

different concentrations, the reason for this is that the rapid uptake of the nanocomposites with a size of approximately $100 \mathrm{~nm}$. Figure $6 \mathrm{Bb}$ shows the $\mathrm{IC}_{50}$ of free DOX and nanocomposites on MCF-7 cells $(7.63 \mu \mathrm{g} / \mathrm{mL}$ to $2.32 \mu \mathrm{g} / \mathrm{mL})$, indicating that both the free DOX and the nanocomposites could cause the loss of MCF-7 cell viability. Compared to the MCF-7 cells, the MCF-7/ADR cells showed a better toxicity tolerance to free DOX, while the nanocomposites could notable reduce the cell viability of MCF-7 and MCF-7/ADR cells. The cytotoxicity experiments demonstrated that the nanocomposites could significantly reverse drug resistance in MCF-7/ ADR cells, as shown by the simultaneous drug-release profiles. As a promising drug delivery platform, the nanocomposites can transport DOX into the cancer cells effectively and serve as a potential drug carrier for synergistic treatment.

After staining with annexin V-APC/PI, the cell apoptosis of MCF-7/ADR was measured by flow cytometry. As shown in Figure 7A, MCF-7/ADR cells exposed to MSNs did not show visible apoptosis after $24 \mathrm{~h}$ of incubation, even though the concentration of MSNs was $40 \mu \mathrm{g} / \mathrm{mL}$, indicating that the MSNs were biocompatible. Free DOX was not able to induce MCF-7/ADR cell apoptosis, which is consistent with the CCK-8 results. The nanocomposites were able to induce cell apoptosis by $10.27 \%$ at a concentration of $0.5 \mu \mathrm{g} / \mathrm{mL}$. The concentration of nanocomposites reached $10.0 \mu \mathrm{g} / \mathrm{mL}$, and cell apoptosis was as high as $55.03 \%$. The apoptosis experiment showed that the nanocomposites did kill MCF-7/ADR cells in proportion to the concentration of nanocomposites. These results suggest that the nanocomposites could make MCF-7/ADR cells more sensitive to DOX and significantly induce apoptosis in cancer cells.

Cell invasion and migration are important processes in breast cancer development and metastasis and have 

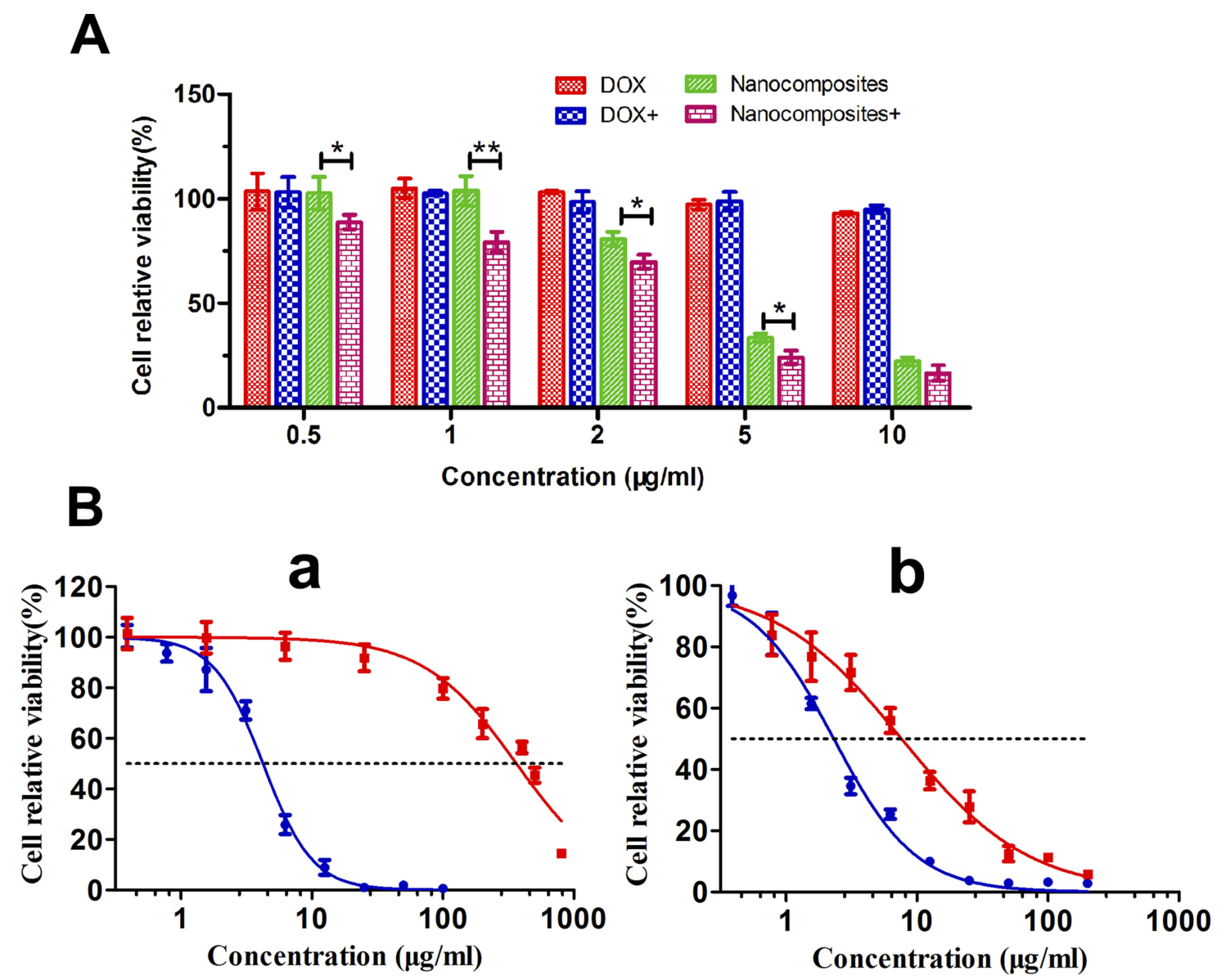

$\rightarrow$ DOX $\quad \rightarrow$ Ce6@MMSN/DOX@FA-PEG-b-PAsp

Figure 6 The therapeutic effect of the nanoparticles.

Notes: (A) Relative viabilities of MCF-7/ADR cells treated with different concentrations of free DOX and nanocomposites with or without light irradiation. (B) Halfmaximal inhibition curve of MCF-7/ADR (a) and MCF-7 cells (b) treated with various concentrations of free DOX and nanocomposites (mean \pm SD, $n=3$; $* P<0.05$, **P $<0.01$ ). Abbreviations: DOX, doxorubicin hydrochloride; Ce6, chlorin e6; MMSN, magnetic mesoporous silica nanoparticle.

become a challenging problem in clinical treatment. ${ }^{40}$ The Transwell assays suggested that treatment with higher doses of nanocomposites can significantly reduce the number of invaded cells, and the effects showed a dose dependent (Figure 7B). Hence, these results suggest that treatment of nanocomposites with higher doses could significantly inhibit the migration and invasion of cells.

\section{Magnetic Targeting, Toxicity, And Antitumor Effects In Vivo}

The small animal MRI was used to study the magnetic targeting of the nanocomposites in vivo (Figure 8A). The $\mathrm{T}_{1}$-weighted MRI image of mice with the magnetic field treatment differed from that without the magnetic field treatment. The images of mice with the magnetic field treatment (Figure 8A1) were darker than those without the magnetic field (Figure 8A2), which indicated that the concentration of nanocomposites was increased in the presence of a magnetic field and that magnetic targeting to the tumor site was highly efficient. Afterward, the mice were executed to study the distribution of nanocomposites in the major organs (stained with Prussian blue) (Figure 8B). Many more nanocomposites were retained in the tumor with the magnetic field treatment than without the magnetic field treatment.

To detect any damage or toxicity to the major organs after intravenous treatment with the normal saline solution, MSNs and nanocomposites in healthy nude mice, the histopathology of the major organs in each group was studied by H\&E staining. There were no obvious morphological differences or side effects between the groups in healthy mice (Figure 8C). Additionally, serum biochemistry was analyzed to illustrate the effects of the nanocomposites on the liver and renal function after the intravenous treatment in mice. The parameters, including T-BIL, TP, 


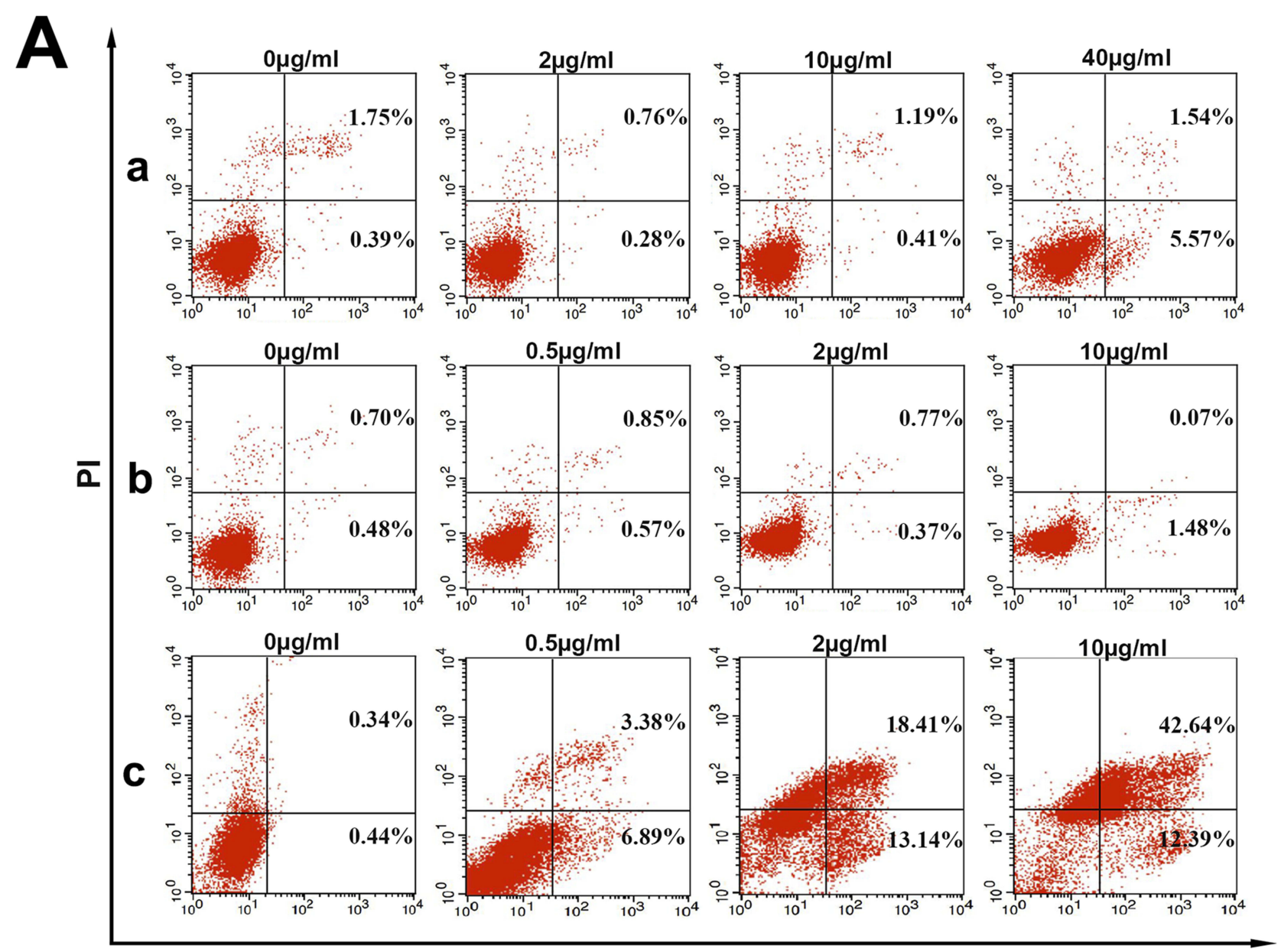

Annexin V-APC

B
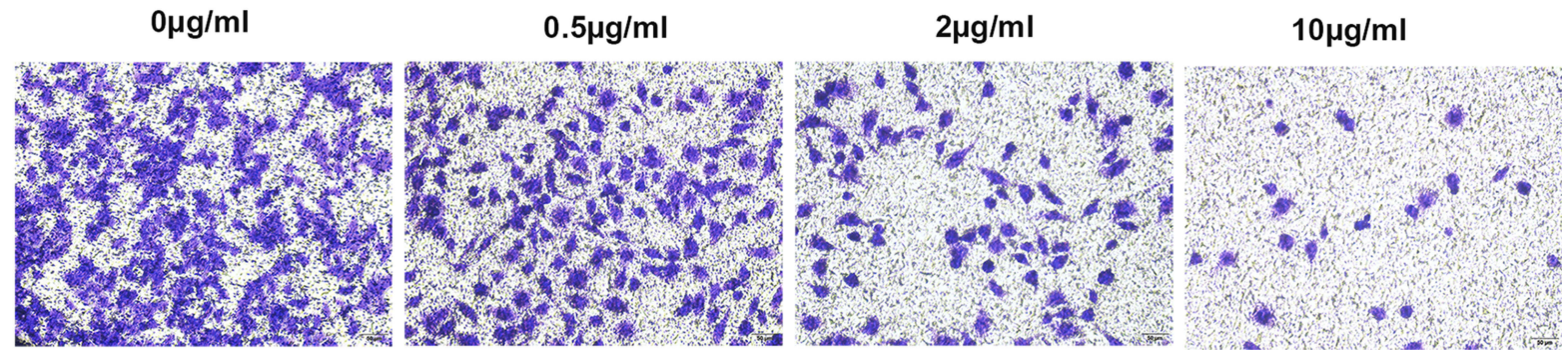

Figure 7 Results of the apoptosis assay and Transwell experiment of the nanocomposites in vitro.

Notes: (A) The apoptosis of MCF-7/ADR cells treated with MSN (a), free DOX (b) and nanocomposites (c) for $24 \mathrm{~h}$. (B) Effects of nanocomposites on the invasion and motility of MCF-7/ADR cells. The cells were cultured with the indicated concentrations of nanocomposites. The cells were stained with crystal violet.

Abbreviations: FITC, fluorescein isothiocyanate; PI, propidium iodide; DOX, doxorubicin hydrochloride; MSN, mesoporous silica nanoparticle.

ALB, ALT, AST, and ALP (indicative of liver function), $\mathrm{UA}, \mathrm{Cr}$, and BUN (indicative of renal function), were examined. ${ }^{41}$ Table 1 shows that the AST of the nanocomposite group increased slightly, but other indicators showed no statistical significance with the control group. The increase in AST was due to the hepatotoxicity of DOX. Furthermore, the serum biochemical analysis showed that there were no significant differences in kidney function between the groups (Table 2). In general, based on the experimental results in vivo, the nanocomposites had good tissue and blood compatibility without serious adverse effects.

We further investigated the antitumor activity of the nanocomposites in vivo (a xenograft nude mouse model bearing MCF-7/ADR tumors). On the eighth day after inoculation, the mice were treated with 1) normal saline 
A

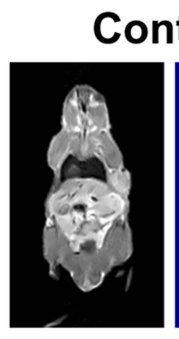

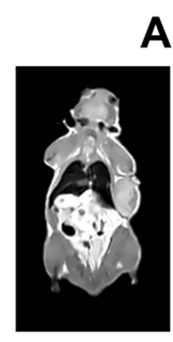

A1

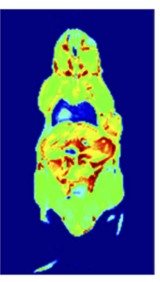

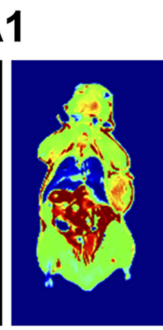

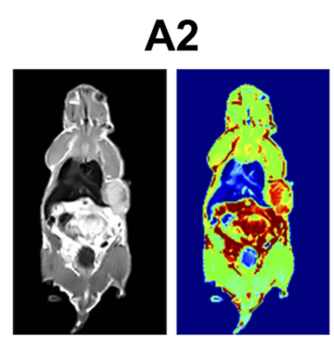

B

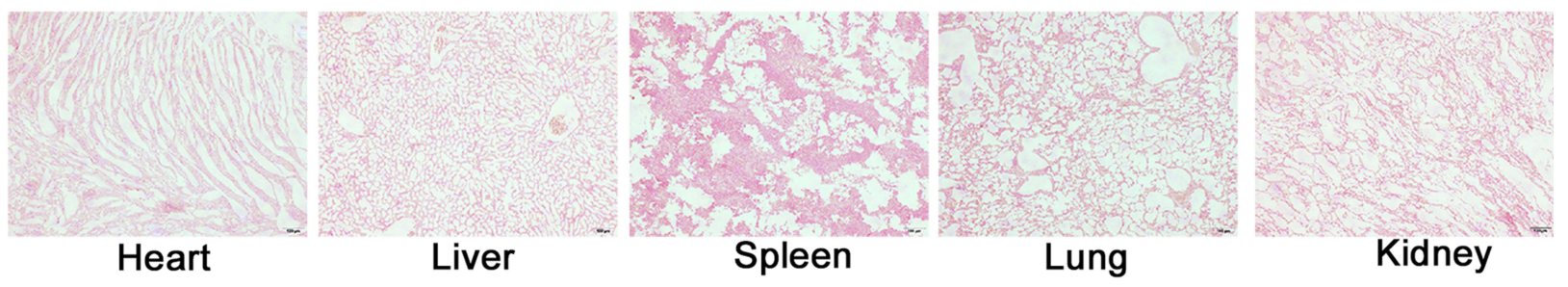

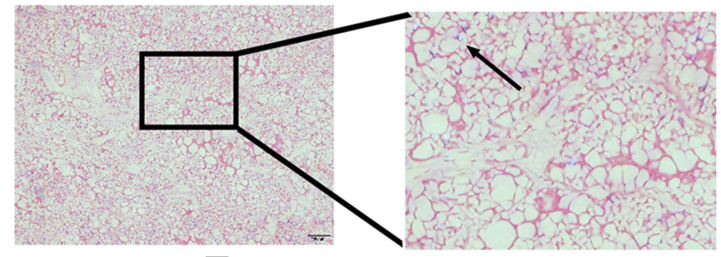

Tumor -

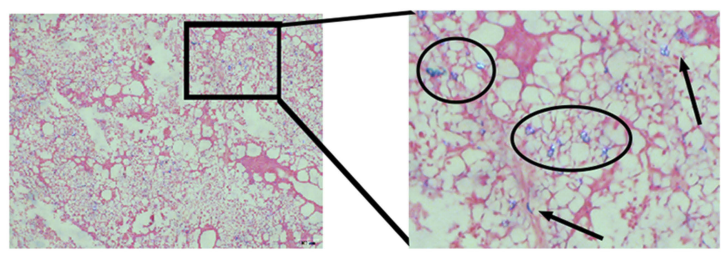

Tumor +

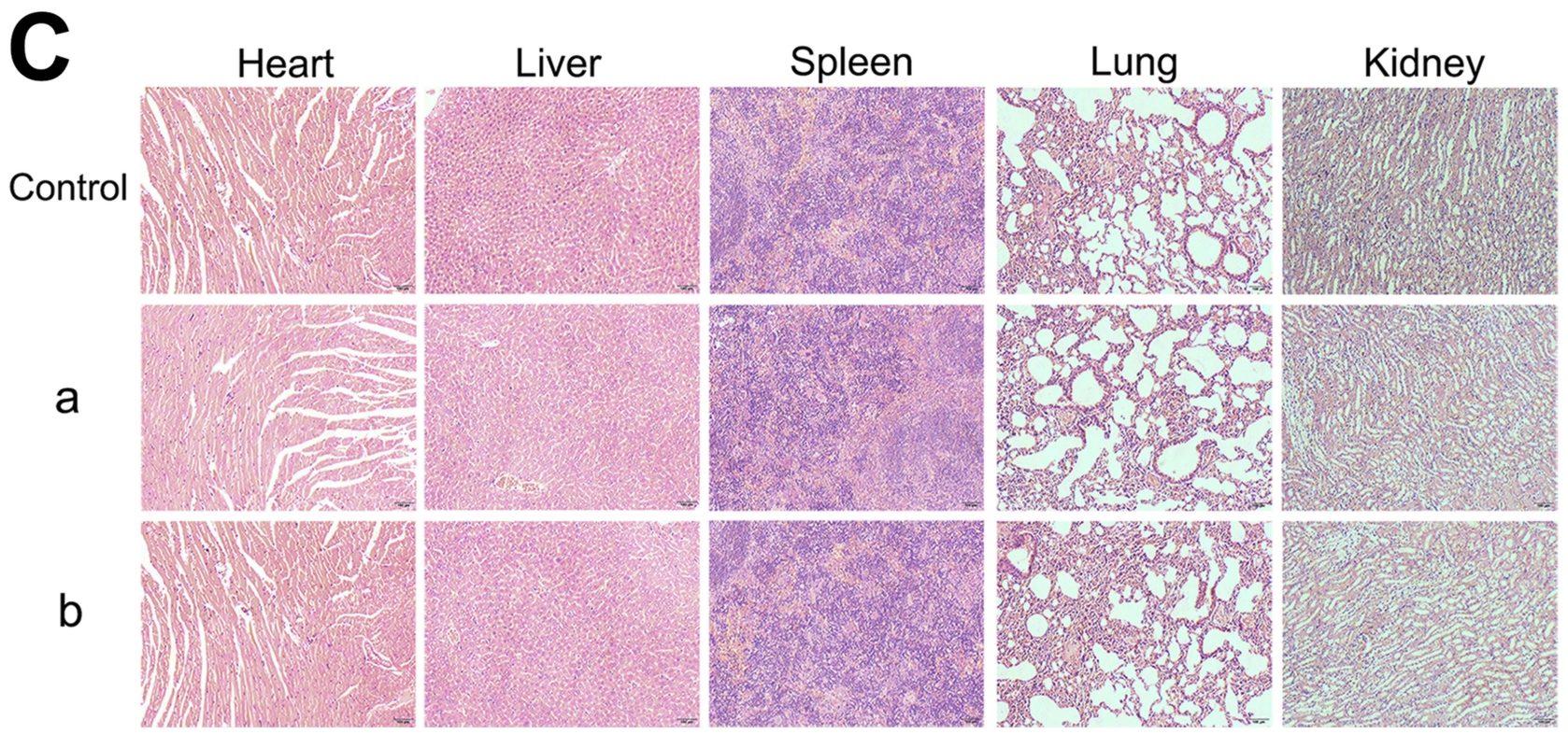

Figure 8 Magnetic targeting and histological analysis.

Notes: (A) $\mathrm{T}_{1}$-weighted MRI images of mice: control, postinjection (AI), and 2-h postinjection with NIB magnet for 30 min (A2). (B) Prussian blue-stained images; the circles and arrows indicate the locations of nanocomposites in the tumor site. (C) The histological characteristics of the main organs after treatment with I $\mathrm{mg} / \mathrm{mL}$ MSN (a) and nanocomposites (b) once a day for 5 days $(\times 200)$.

Abbreviations: MRI, magnetic resonance image; MMSN, magnetic mesoporous silica nanoparticle; NIB, neodymium, iron and boron magnet; MSN, mesoporous silica nanoparticle; H\&E, hematoxylin and eosin.

solution, 2) free DOX, 3) nanocomposites-, and 4) nanocomposites + every 2 days. In addition, the body weights and tumor volumes of the mice were monitored regularly.
There were no significant differences in body weight during the treatment period, indicating that the systemic toxicity was low (Figure 9A). As shown in Figure 9B, 
Table I Serum Biochemical Analysis Of The Liver Function In Nude Mice After Intravenous Treatments With I mg/mL MSN And Nanocomposites Once A Day For 5 Days. $(n=5)$

\begin{tabular}{|l|l|l|l|l|l|l|}
\hline Group & T-BIL $(\boldsymbol{\mu m o l} / \mathbf{L})$ & TP $(\mathbf{g} / \mathbf{L})$ & ALB $(\mathbf{g} / \mathbf{L})$ & AST $(\mathbf{U} / \mathbf{L})$ & ALT (U/L) & ALP (U/L) \\
\hline Control & $1.21 \pm 0.13$ & $42.25 \pm 3.04$ & $17.40 \pm 1.41$ & $109.5 \pm 0.71$ & $35.5 \pm 0.71$ & $94.5 \pm 10.61$ \\
MSN & $1.14 \pm 0.17$ & $43.16 \pm 2.45$ & $18.07 \pm 1.52$ & $112.5 \pm 0.71$ & $37.5 \pm 1.53$ & $96.5 \pm 8.56$ \\
Nanocomposites & $1.08 \pm 0.26$ & $50.35 \pm 0.64$ & $24.55 \pm 1.77$ & $170.5 \pm 2.20$ & $44.5 \pm 2.12$ & $100.5 \pm 7.78$ \\
\hline
\end{tabular}

Abbreviations: T-BIL, total bilirubin; TP, total protein; ALB, albumin; AST, glutamic-oxalacetic transaminase; ALT, glutamic-pyruvic transaminase; ALP, alkaline phosphatase; MSN, mesoporous silica nanoparticle.

Table 2 Serum Biochemical Analysis Of The Renal Function In Nude Mice After Intravenous Treatments With I mg/mL MSN And Nanocomposites Once A Day For 5 Days. $(n=5)$

\begin{tabular}{|l|l|l|l|}
\hline Group & BUN (mmol/L) & Cr $(\mu \mathrm{mol} / \mathbf{L})$ & UA ( $\mu \mathrm{mol} / \mathbf{L})$ \\
\hline Control & $11.01 \pm 0.41$ & $17.0 \pm 1.73$ & $559.7 \pm 56.43$ \\
MSN & $11.36 \pm 0.37$ & $16.9 \pm 1.84$ & $568.3 \pm 64.71$ \\
Nanocomposites & $11.50 \pm 0.21$ & $16.5 \pm 2.12$ & $613.0 \pm 36.77$ \\
\hline
\end{tabular}

Abbreviations: BUN, blood urea nitrogen; Cr, creatinine; UA, uric acid; MSN, mesoporous silica nanoparticle.
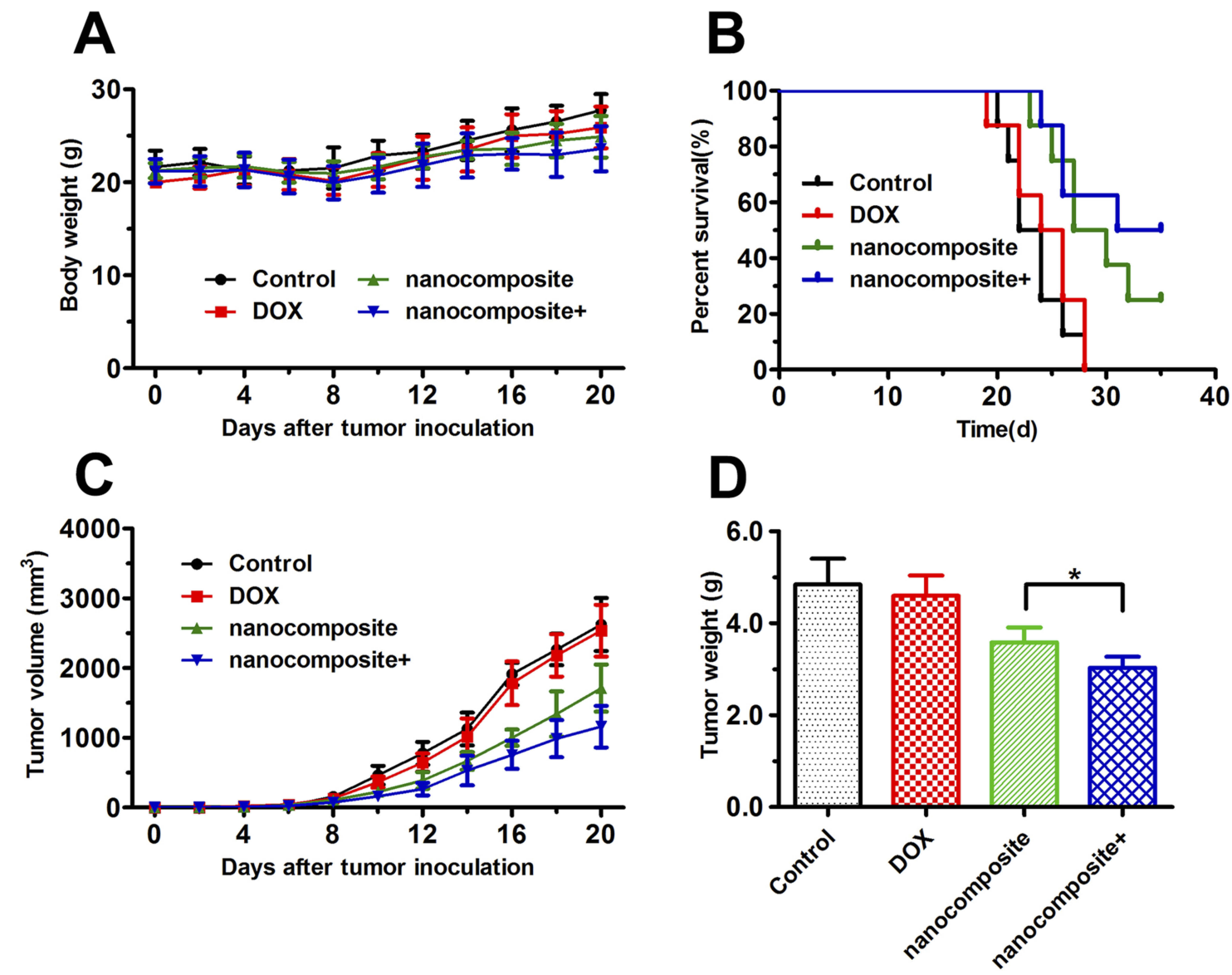

Figure 9 Antitumor experiments in vivo.

Notes: (A) The body weight changes of BALB/c nude mice during the therapeutic period. (B) Survival rate of MCF-7/ADR tumor-bearing BALB/C nude mice. (C) The tumor volume evolution of mice in different groups during the therapeutic period. (D) The weight of the excised tumor tissues from all groups. The data are expressed as the mean $\pm \mathrm{SD}(\mathrm{n}=8)$. $* \mathrm{P}<0.05$.

Abbreviations: DOX, doxorubicin hydrochloride; MMSN, magnetic mesoporous silica nanoparticle; NIB, neodymium, iron and boron magnet.

compared with that in the control group, the mean survival duration of the mice in the nanocomposite groups was significantly prolonged, especially in the nanocomposite group with the magnetic field treatment. Figure $9 \mathrm{C}$ and $\mathrm{D}$ 
shows the tumor volume curves and tumor weight. Similar curves were obtained for the control and free DOX groups, suggesting that free DOX could not inhibit the growth of tumors. The nanocomposite group within or without the magnetic field treatment presented a better antitumor effect than the free drug group, indicating that inhibition of the tumors was significantly different. Undoubtedly, the nanocomposites with the magnetic field group presented the best therapeutic effect; the tumor volumes and weight were the smallest. These in vivo results indicated that the nanocomposites could effectively inhibit the growth of tumor and improve the survival rate of tumor-bearing mice, which could greatly increase the enrichment and endocytosis of DOX and enhance its cellular release in the tumor site. Additionally, these in vivo results confirmed with the results of the in vitro tests.

\section{Conclusion}

In summary, a functional nanocomposite based on a magnetic and $\mathrm{pH}$ dual-responsive MSN was successfully developed for breast cancer chemo/photodynamic therapy. The MSN was designed as the core, whereas the $\mathrm{pH}$-responsive polymer FAPEG- $b$-PAsp was grafted onto the surface of MSN by amidation reaction. The nanocomposite displayed excellent cellular uptake, overcame chemotherapeutic resistance and induced apoptosis in MCF-7/ADR cells. Additionally, the nanocomposites both exhibited excellent tumor-targeting ability under a magnetic field and effectively suppressed tumor growth with laser irradiation in vivo. No serious adverse effects were observed after treatment with the nanocomposites. This nanocomposite may be a promising platform in the combined treatment of cancers in the future.

\section{Acknowledgments}

This work was supported by a grant from National Key R\&D Program of China (2016YFC1303100), the National Natural Science Foundation of China (21778022), Shanghai Natural Science Foundation (16ZR1444200), and National Science Foundation for Young Scientists of China (81603124).

\section{Disclosure}

The authors report no conflicts of interest in this work.

\section{References}

1. Kucharczyk MJ, Parpia S, Walker-Dilks C, Banfield L, Swaminath A. Ablative therapies in metastatic breast cancer: a systematic review. Breast Cancer Res Treat. 2017;164(1):13-25. doi:10.1007/s10549017-4228-2
2. Siegel RL, Miller KD, Jemal A. Cancer statistics, 2019. CA Cancer J Clin. 2019;69(1):7-34. doi:10.3322/caac.21551

3. Shreya AB, Raut SY, Managuli RS, Udupa N, Mutalik S. Active targeting of drugs and bioactive molecules via oral administration by ligand-conjugated lipidic nanocarriers: recent advances. AAPS PharmSciTech. 2019;20(1):20. doi:10.1208/s12249-018-1262-2

4. Wijdeven RH, Pang B, Assaraf YG, Neefjes J. Old drugs, novel ways out: drug resistance toward cytotoxic chemotherapeutics. Drug Resist Updat. 2016;28:65-81. doi:10.1016/j.drup.2016.07.001

5. Mahmoudi K, Garvey KL, Bouras A, et al. 5-aminolevulinic acid photodynamic therapy for the treatment of high-grade gliomas. $J$ Neurooncol. 2019;141(3):595-607. doi:10.1007/s11060-019-03103-4

6. Banerjee SM, MacRobert AJ, Mosse CA, Periera B, Bown SG, Keshtgar MRS. Photodynamic therapy: inception to application in breast cancer. Breast. 2017;31:105-113. doi:10.1016/j.breast.2016.09.016

7. Yoon JH, Yoon HE, Kim O, Kim SK, Ahn SG, Kang KW. The enhanced anti-cancer effect of hexenyl ester of 5-aminolaevulinic acid photodynamic therapy in adriamycin-resistant compared to non-resistant breast cancer cells. Lasers Surg Med. 2012;44(1):7686. doi:10.1002/1sm.21154

8. Denkova AG, de Kruijff RM, Serra-Crespo P. Nanocarrier-mediated photochemotherapy and photoradiotherapy. Adv Healthc Mater. 2018;7(8):1701211. doi:10.1002/adhm.201701211

9. Biteghe FAN, Davids LM. A combination of photodynamic therapy and chemotherapy displays a differential cytotoxic effect on human metastatic melanoma cells. J Photochem Photobiol B. 2017;166:1827. doi:10.1016/j.jphotobiol.2016.11.004

10. Kwiatkowski S, Knap B, Przystupski D, et al. Photodynamic therapy mechanisms, photosensitizers and combinations. Biomed Pharmacother. 2018;106:1098-1107. doi:10.1016/j.biopha.2018.06.155

11. Cheng CT, Castro G, Liu CH, Lau P. Advanced nanotechnology: an arsenal to enhance immunotherapy in fighting cancer. Clin Chim Acta. 2019;492:12-19. doi:10.1016/j.cca.2019.01.027

12. Wang Z, Deng X, Ding J, Zhou W, Zheng X, Tang G. Mechanisms of drug release in $\mathrm{pH}$-sensitive micelles for tumour targeted drug delivery system: a review. Int $J$ Pharm. 2018;535(1-2):253-260. doi:10.1016/j.ijpharm.2017.10.064

13. Zhou F, Teng F, Deng P, Meng N, Song Z, Feng R. Recent progress of nano-drug delivery system for liver cancer treatment. Anticancer Agents Med Chem. 2018;17(14):1884-1897. doi:10.217 4/1871520617666170713151149

14. Isoglu I, Ozsoy Y, Isoglu S. Advances in micelle-based drug delivery: cross-linked systems. Curr Top Med Chem. 2017;17(13):1469-1489. doi:10.2174/156802661709170213214101

15. Maeki M, Kimura N, Sato Y, Harashima H, Tokeshi M. Advances in microfluidics for lipid nanoparticles and extracellular vesicles and applications in drug delivery systems. Adv Drug Deliv Rev. 2018;128:84-100. doi:10.1016/j.addr.2018.03.008

16. Carazo E, Borrego-Sánchez A, García-Villén F, et al. Advanced inorganic nanosystems for skin drug delivery. Chem Rec. 2018;18 (7-8):891-899. doi:10.1002/tcr.201700061

17. Olov N, Bagheri-Khoulenjani S, Mirzadeh H. Combinational drug delivery using nanocarriers for breast cancer treatments: a review. $J$ Biomed Mater Res A. 2018;106(8):2272-2283. doi:10.1002/jbm. a.36410

18. Castillo RR, Colilla M, Vallet-Regí M. Advances in mesoporous silica-based nanocarriers for co-delivery and combination therapy against cancer. Expert Opin Drug Deliv. 2017;14(2):229-243. doi:10.1080/17425247.2016.1211637

19. Zhang W, Liu M, Liu A, Zhai G. Advances in functionalized mesoporous silica nanoparticles for tumor targeted drug delivery and theranostics. Curr Pharm Des. 2017;23(23):3367-3382. doi:10.2174/1381612822666161025153619

20. Wen J, Yang K, Liu F, Li H, Xu Y, Sun S. Diverse gatekeepers for mesoporous silica nanoparticle based drug delivery systems. Chem Soc Rev. 2017;46(19):6024-6045. doi:10.1039/C7CS00219J 
21. Stöber W, Fink A, Bohn E. Controlled growth of monodisperse silica spheres in the micron size range. J Colloid Interface Sci. 1968;26 (1):62-69. doi:10.1016/0021-9797(68)90272-5

22. Wang X, Zhang Y, Luo W, et al. Synthesis of ordered mesoporous silica with tunable morphologies and pore sizes via a nonpolar solvent-assisted stöber method. Chem Mater. 2016;28(7):23562362. doi:10.1021/acs.chemmater.6b00499

23. Mehravi B, Ardestani MS, Damercheli M, et al. Breast cancer cells imaging by targeting methionine transporters with gadolinium-based nanoprobe. Mol Imaging Biol. 2014;16(4):519-528. doi:10.1007/ s11307-014-0733-4

24. Shahabi S, Döscher S, Bollhorst T, et al. Enhancing cellular uptake and doxorubicin delivery of mesoporous silica nanoparticles via surface functionalization: effects of serum. ACS Appl Mater Interfaces. 2015;7(48):26880-26891. doi:10.1021/acsami.5b09483

25. Liang X, Wang X, Zhuang J, Chen Y, Wang D, Li Y. Synthesis of nearly monodisperse iron oxide and oxyhydroxide nanocrystals. $A d v$ Funct Mater. 2006;16(14):1805-1813. doi:10.1002/(ISSN)1616-3028

26. Lattuada M, Hatton TA. Functionalization of monodisperse magnetic nanoparticles. Langmuir. 2007;23(4):2158-2168. doi:10.1021/la062092x

27. Lee JE, Lee N, Kim H, et al. Uniform mesoporous dye-doped silica nanoparticles decorated with multiple magnetite nanocrystals for simultaneous enhanced magnetic resonance imaging, fluorescence imaging, and drug delivery. J Am Chem Soc. 2010;132(2):552-557. doi:10.1021/ja905793q

28. Shi S, Zhu X, Zhao Z, et al. Photothermally enhanced photodynamic therapy based on mesoporous Pd@Ag@mSiO2 nanocarriers. J Mater Chem B. 2013;1(8):1133. doi:10.1039/c2tb00376g

29. Zhan J, Ma Z, Wang D, et al. Magnetic and $\mathrm{pH}$ dual-responsive mesoporous silica nanocomposites for effective and low-toxic photodynamic therapy. Int J Nanomed. 2017;12:2733-2748. doi:10.2147/ IJN.S127528

30. Frey NA, Peng S, Cheng K, Sun S. Magnetic nanoparticles: synthesis, functionalization, and applications in bioimaging and magnetic energy storage. Chem Soc Rev. 2009;38(9):2532. doi:10.1039/b815548h

31. Zhou JL, Song F, Tian JF, Nie WC, Wang XL, Wang YZ. Electrostatic wrapping of doxorubicin with curdlan to construct an efficient pH-responsive drug delivery system. Nanotechnology. 2017;28(29):295601. doi:10.1088/1361-6528/aa75b5
32. Wang X, Zhuang J, Peng Q, Li Y. A general strategy for nanocrystal synthesis. Nature. 2005;437(7055):121-124. doi:10.1038/nature03968

33. Wu B, Lu ST, Zhang LJ, Zhuo RX, Xu HB, Huang SW. Codelivery of doxorubicin and triptolide with reduction-sensitive lipid-polymer hybrid nanoparticles for in vitro and in vivo synergistic cancer treatment. Int J Nanomed. 2017;12:1853-1862. doi:10.2147/IJN.S131235

34. Kalyane D, Raval N, Maheshwari R, Tambe V, Kalia K, Tekade RK. Employment of enhanced permeability and retention effect (EPR): nanoparticle-based precision tools for targeting of therapeutic and diagnostic agent in cancer. Mater Sci Eng C. 2019;98:1252-1276. doi:10.1016/j.msec.2019.01.066

35. Gong C, Hu C, Gu F, et al. Co-delivery of autophagy inhibitor ATG7 siRNA and docetaxel for breast cancer treatment. J Control Release. 2017;266:272-286. doi:10.1016/j.jconrel.2017.09.042

36. Lin L, Xiong L, Wen Y, et al. Active targeting of nano-photosensitizer delivery systems for photodynamic therapy of cancer stem cells. J Biomed Nanotechnol. 2015;11(4):531-554.

37. Zhang C, Zhao X, Guo S, Lin T, Guo H. Highly effective photothermal chemotherapy with $\mathrm{pH}$-responsive polymer-coated drugloaded melanin-like nanoparticles. Int J Nanomed. 2017;12:18271840. doi:10.2147/IJN.S130539

38. Liu Y, Workalemahu B, Jiang X. The effects of physicochemical properties of nanomaterials on their cellular uptake in vitro and in vivo. Small. 2017;13(43):1701815. doi:10.1002/smll.v13.43

39. Li X, Wang L, She L, et al. Immunotoxicity assessment of ordered mesoporous carbon nanoparticles modified with PVP/PEG. Colloids Surf B Biointerfaces. 2018;171:485-493. doi:10.1016/j. colsurfb.2018.07.036

40. Schmucker H, Blanding WM, Mook JM, et al. Amphiregulin regulates proliferation and migration of HER2-positive breast cancer cells. Cell Oncol. 2018;41(2):159-168. doi:10.1007/s13402-017-0363-3

41. Khayyat L, Essawy A, Sorour J, Soffar A. Tartrazine induces structural and functional aberrations and genotoxic effects in vivo. Peer J. 2017;5:e3041. doi:10.7717/peerj.3041
International Journal of Nanomedicine

\section{Publish your work in this journal}

The International Journal of Nanomedicine is an international, peerreviewed journal focusing on the application of nanotechnology in diagnostics, therapeutics, and drug delivery systems throughout the biomedical field. This journal is indexed on PubMed Central, MedLine, CAS, SciSearch ${ }^{\circledR}$, Current Contents ${ }^{\mathbb{R}} /$ Clinical Medicine,

\section{Dovepress}

Journal Citation Reports/Science Edition, EMBase, Scopus and the Elsevier Bibliographic databases. The manuscript management system is completely online and includes a very quick and fair peer-review

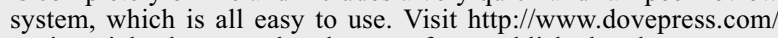
testimonials.php to read real quotes from published authors. 